\title{
Monitoring System for Glycemic Control in Patients with Type 2 Diabetes Mellitus, Based on Mobile Technology, Telemetry, and Health Education
}

\author{
Eduardo Toledo, Daniel Cárdenas, Miguel Angulo, Edgard Oporto \\ Universidad de Lima \\ Av. Javier Prado Este Cuadra 46 S/N, Santiago de Surco, Lima, Perú \\ etoledo@ulima.edu.pe; decarden@ulima.edu.pe; miguelangulo@icluod.com; edgard.oporto@pucp.edu.pe
}

\section{Extended Abstract}

Type 2 diabetes mellitus corresponds to approximately 95\% of people diagnosed with diabetes. From 1980 to 2014 , there has been an overall increase in the prevalence of the disease from $4.7 \%$ to $8.5 \%$, according to World Health Organization (WHO) [1]. Furthermore, it is estimated that by the year 2030, diabetes will be the seventh cause of death worldwide, which is why it is necessary for governments to establish policies and programs to ensure equitable access to essential technologies for diagnosis and comprehensive care.

Currently, glycemic control by diabetic patients is usually inadequate and this is due to many factors, like daily food intake [2] and the rate of adherence to medication by the patients which is on average only 50\% [3]. Additionally, there are several physiological parameters that influence the regulation of glucose such as the quality of sleep [4], and infections [5], among others, making it difficult for patients to control their disease. The lack of glucose levels control makes the disease more complex, resulting in the following complications: blindness, kidney failure, heart disease, stroke, and limb amputation, among others. The consequences of these complications can even be fatal for patients, who are not able to stop or regulate the progression of their disease. For this reason, diabetic patients need access to a systematic, continuous, and organized care provided by a qualified healthcare team.

In this research, we propose the development of a system that gives the patient the ability to empower themselves in the management, control, and treatment of their disease, including appropriate follow up, monitoring, and education by health professionals. The system consists of a mobile application integrated to telemetry devices. The devices developed (glucometer, pillbox, weight scale, and sleep sensor) will allow the quantification of the parameters that influence the glycemic level. The mobile application captures the information received by the devices on a daily basis, sends this information to a computer platform, and shows data to users (patient and doctor).

Additionally, we have developed a web-based computer platform. This platform contains an algorithm that processes the information registered in a specialized database and provides the patient with recommendations that allow him to adopt positive choices to the evolution of his/her disease. The follow-up that the doctor will perform through the system and the feedback that will be provided through the mobile application, will allow each patient to maintain their glucose level within acceptable ranges, which guarantees control of their disease.

Sixty patients diagnosed with type 2 diabetes mellitus will participate in the validation of this system. The patients' level of glycosylated hemoglobin will be measured at the beginning and at the end of the study. The participants will be divided into two groups: an experimental group, consisting of patients who will use the system for a period of three months, and a control group, made up of patients who will not use the system for the same period and who will receive standard medical care. We hypothesize that the proper use of this system will improve the prognosis of patients through the expected reduction of elevated levels of glycosylated hemoglobin at the end of the study period [6].

\section{References}

[1] C. Mathers, D. Loncar, "Projections of global mortality and burden of disease from 2002 to 2030," PLoS Med, vol. 3, no. 11 , p. e442, 2006.

[2] D. Ludwig, "The Glycemic index, Physiological Mechanisms Relating to Obesity, Diabetes, and Cardiovascular Disease," JAMA, vol. 287, no. 18, pp. 2414-2423, 2002. 
[3] J. Cramer, "A Systematic Review of Adherence with Medications for Diabetes," Diabetes Care, vol. 27, no. 5, pp. 1218-1224, 2004.

[4] K. Spiegel, K. Knutson, R. Leproult, E. Tasali, E. Cauter, "Sleep loss: a novel risk factor for insulin resistance and Type 2 diabetes, ” Journal of Applied Physiology, vol. 99, no. 5, pp. 2008-2019, 2005.

[5] S. Gupta, J. Koirala, R. Khardori, N. Khardori, "Infections in diabetes mellitus and hyperglycemia," Infect Dis Clin North Am., vol. 21, no. 3, pp. 617-38, vii, 2007.

[6] D. Sacks, M. Arnold, G. Bakris, D. Bruns, A. Horvath, M. Kirkman, A. Lernmark, B. Metzger and D. Nathan, "Guidelines and Recommendations for Laboratory Analysis in the Diagnosis and Management of Diabetes Mellitus," Diabetes Care, vol. 34, no. 6, pp. e61-e99, 2011. 